\title{
Engineering of a wheat germ expression system to provide compatibility with a high throughput pET-based cloning platform
}

\author{
Li Zhao $\cdot$ Kate Q. Zhao $\cdot$ Robin Hurst $\cdot$ Michael R. Slater • \\ Thomas B. Acton · G. V. T. Swapna · Ritu Shastry • \\ Gregory J. Kornhaber · Gaetano T. Montelione
}

Received: 15 December 2009/Accepted: 11 June 2010/Published online: 24 June 2010

(C) The Author(s) 2010. This article is published with open access at Springerlink.com

\begin{abstract}
Wheat germ cell-free methods provide an important approach for the production of eukaryotic proteins. We have developed a protein expression vector for the TNT ${ }^{\circledR}$ SP6 High-Yield Wheat Germ Cell-Free (TNT WGCF) expression system (Promega) that is also compatible with our T7-based Escherichia coli intracellular expression vector pET15_NESG. This allows cloning of the same PCR product into either one of several pET_NESG vectors and this modified WGCF vector (pWGHisAmp) by In-Fusion LIC cloning (Zhu et al. in Biotechniques 43:354-359, 2007). Integration of these two
\end{abstract}

Originally presented at the NIGMS Protein Structure Initiative Workshop on Enabling Technologies for Structure Biology, March 4-6, 2009.

Electronic supplementary material The online version of this article (doi:10.1007/s10969-010-9093-8) contains supplementary material, which is available to authorized users.

L. Zhao · G. T. Montelione

Center for Advanced Biotechnology and Medicine, Robert

Wood Johnson Medical School, University of Medicine

and Dentistry of New Jersey, Piscataway, NJ 08854, USA

L. Zhao · T. B. Acton - G. V. T. Swapna - R. Shastry ·

G. J. Kornhaber · G. T. Montelione

Northeast Structural Genomics Consortium,

Piscataway, NJ, USA

K. Q. Zhao · R. Hurst · M. R. Slater

Promega Corp., 2800 Woods Hollow Road,

Madison, WI 53711, USA

T. B. Acton - G. V. T. Swapna - R. Shastry ·

G. J. Kornhaber · G. T. Montelione ( $\square)$

Center for Advanced Biotechnology and Medicine, Department

of Molecular Biology and Biochemistry, Rutgers, The State

University of New Jersey, Piscataway, NJ 08854, USA

e-mail: guy@cabm.rutgers.edu vector systems allowed us to explore the efficacy of the TNT WGCF system by comparing the expression and solubility characteristics of 59 human protein constructs in both WGCF and pET15_NESG E. coli intracellular expression. While only $30 \%$ of these human proteins could be produced in soluble form using the pET15_NESG based system, some $70 \%$ could be produced in soluble form using the TNT WGCF system. This high success rate underscores the importance of eukaryotic expression host systems like the TNT WGCF system for eukaryotic protein production in a structural genomics sample production pipeline. To further demonstrate the value of this WGCF system in producing protein suitable for structural studies, we scaled up, purified, and analyzed by $2 \mathrm{D}$ NMR two ${ }^{15} \mathrm{~N}-,{ }^{13} \mathrm{C}$ enriched human proteins. The results of this study indicate that the TNT WGCF system is a successful salvage pathway for producing samples of difficult-to-express small human proteins for NMR studies, providing an important complementary pathway for eukaryotic sample production in the NESG NMR structure production pipeline.

Keywords Wheat germ cell free expression system . Micro cryo NMR probe - Structural genomics .

Eukaryotic protein expression $\cdot$ Isotope enrichment

\section{Introduction}

Cell-free expression systems are capable of generating small quantities of soluble eukaryotic proteins in instances where traditional bacterial expression systems have failed $[7,17]$. Cell-free systems can also accommodate a variety of isotopic enrichment schemes and are capable of routinely generating labeled protein in quantities sufficient for structural analysis by solution NMR [12, 13]. The 
Northeast Structural Genomics Consortium (NESG, www.nesg.org), a large-scale center funded by the National Institutes of General Medical Sciences (NIGMS), has to date created some 5,000 eukaryotic protein expression plasmids, mostly using modified pET vectors [pET_NESG vectors [1]] for cell-based production in E. coli. Although our success over the past 5 years in producing a specific protein is greatly enhanced by cloning multiple constructs of the same target, even using this strategy success rates in producing a soluble construct for a specific eukaryotic protein in our $E$. coli based expression system (26\%) is significantly lower than the corresponding success rates for targets of prokaryotic origin (42\%) (statistics posted at www.nesg.org). Within the NIGMS Protein Structure Initiative, the Center for Eukaryotic Structural Genomics (CESG) has pioneered the use of wheat germ cell-free systems for producing eukaryotic proteins for a wide range of applications (see for example [17, 18]). The wheat germ cell-free system is particularly advantageous for preparing samples for NMR studies, as it is relatively inexpensive to incorporate ${ }^{15} \mathrm{~N}$ and ${ }^{13} \mathrm{C}$ isotopes when compared with other eukaryotic expression hosts. Here we describe progress in developing a cell-free protein expression pipeline that parallels the NESG HTP pET-based E. coli expression pipeline [1], allowing routine use of WGCF systems for salvage of certain eukaryotic proteins.

There are three widely utilized cell-free systems each based on cellular extracts [7]. These are derived from either E. coli, rabbit reticulocytes, or wheat germ. Such extracts contain all of the macromolecular machinery required for translation, such as ribosomes, elongation and termination factors, tRNAs, etc. E. coli cell-free expression systems have been used successfully in structural genomics [2, 4]; indeed the Riken Structural Genomics/Proteomics Initiative (RSGI) protein production pipeline is based on this type of cell-free translation. Unfortunately eukaryotic proteins often possess multiple domains, which tend to missfold in prokaryotic (e.g., E. coli) expression systems [16]. The rabbit reticulocyte system tends to have low efficiency, and hence not cost effective for producing the quantities of protein necessary for protein structure determination [7]. Wheat germ extracts, however, have been demonstrated to be well-suited for isotopic enrichment, and for cost-effective production of hundred microgram quantities of proteins sufficient for NMR studies [12, 13, 15, 17, 18].

With support from the Protein Structure Initiative of the NIGMS, the NESG has successfully constructed a protein structure production pipeline centered on an automated HTP multiplexed cloning platform [1]. The platform is fully integrated with a laboratory information management system and PCR primer/construct design tools [8]. To take full advantage of the NESG protein production infrastructure, we require a modified wheat germ cell-free (WGCF) vector that is compatible with the current cloning and expression procedures. In particular, we require a system that is compatible with the same PCR products used in our modified pET_NESG vectors (described in Acton et al. [1]).

Here we describe modifications to the Promega TNT ${ }^{\circledR}$ SP6 High-Yield Wheat Germ Cell-Free (TNT WGCF) expression system that allow utilization of the same PCR products generated for the NESG HTP pET-based cloning platform. Utilization of the TNT WGCF system avoids the cumbersome handling of mRNA, by coupling the processes of transcription and translation in one optimized extract [20]. This is achieved by the addition of SP6 RNA polymerase to the WGCF reaction and the inclusion of an SP6 promoter to the template DNA. Other commercially available systems require the separate generation of mRNA template. This finite mRNA supply is then added to the WGCF protein translation reaction. By contrast, the Promega $\mathrm{TNT}^{\circledR}$ requires only the addition of DNA template for protein expression.

Promega provides a number of vectors that are compatible with the TNT WGCF system. In order to make the cloning and protein purification compatible with the current NESG platform, the pTSHQn vector (based on the Promega Riboprobe ${ }^{\circledR}$ System Vector pSP64) was subjected to several modifications. We describe the new vector, pWGHisAmp and demonstrate its use with the TNT WGCF system in obtaining good expression and solubility for eukaryotic protein targets. Using the NESG protein production platform, a set of 59 human protein constructs were then cloned and expressed in the TNT WGCF system and, in parallel, in our intracellular pET15_NESG E. coli system. To gauge the feasibility of using such samples for protein NMR structure applications, two of these human proteins were also isotope enriched and subsequently analyzed by 2D NMR using a micro cryo NMR probe. The TNT WGCF approach represents a viable salvage pathway of the NESG structure production pipeline for eukaryotic protein targets exhibiting poor expression and/or solubility in intracellular E. coli host systems.

\section{Materials and methods}

Creation of a WGCF expression vector compatible with NESG HTP cloning pipeline

The pTSHQn $\left(\operatorname{Kan}^{\mathrm{R}}\right)$ vector (Promega) was modified to allow cloning of the same PCR product into the modified WGCF expression vector or our pET15_NESG vector for T7-based E. coli intracelluar expression. pET15_NESG produces proteins with a short $\mathrm{N}$-terminal non-cleavable 
hexaHis tag (MGHHHHHHSH). The backbone of pTSHQn was PCR amplified with the primers WG-F (5'-GTGATGG TGATGGCCCATGGCGAATTCTCCTTATTCTATAG-3') and WG-R (5'-GAGATCCGGCTGCTAAGGATCCTCTA GAGTCGACCTGC- $3^{\prime}$ ). Following PCR, the reaction mixture was treated with DpnI to destroy the pTSHQn template and subjected to agarose gel electrophoresis. The amplified backbone of pTSHQn was excised from the gel and purified. The pET15_NESG linker, including the coding region for a hexaHis-tag, was amplified by PCR from the NESG-modified pET15_NESG plasmid [1] with the primers pET15_NESG linkerF (5'-ATGGGCCATCAC CATCACCA- $3^{\prime}$ ) and pET15_NESG linkerR (5'-TTAGC AGCCGGATCTCGAG- $3^{\prime}$ ). The amplified pET15_NESG linker was also gel purified and was then subcloned into the amplified pTSHQn backbone by the In-Fusion ${ }^{\mathrm{TM}}$ (Takara) ligation independent cloning method [21]. Transformation into $E$. coli $X L-10$ gold cells (Stratagene) was followed by selection on $\mathrm{LB} / \mathrm{Kan}$ medium. The resulting recombinant clones were screened by PCR, and a correct clone, designated pWGHisKan, was validated by DNA sequencing.

To replace the kanamycin resistance gene of pWGHisKan with an ampicillin resistance gene, required for further standardization with the NESG cloning pipeline, pWGHisKan was PCR amplified excluding the kanamycin resistance gene using the primers WGHisF (5'-AACCATTACGTA GAAAGCCAGTCCGCAG-3') and WGHisR (5'-TTGGTA ATTCGAAATGACCGACCAAGCG- $3^{\prime}$ ). The ampicillin resistance gene from pET15_NESG was also amplified utilizing the primers Amp-F (5'-TTCTACGTAATGGTTT CTTAGACGTCAGG-3') and Amp-R (5'-ATTTCGAAT TACCAATGCTTAATCAGTGAG- $3^{\prime}$ ). The two PCR products were gel purified, subjected to In-Fusion ${ }^{\mathrm{TM}}$ LIC, transformed into $X L-10$ gold cells, and selected on LB/Amp medium. Finally, the resulting pET-compatible WGCF expression plasmid, designated pWGHisAmp, was sequenced verified. The resulting expression vector provides proteins with an $\mathrm{N}$-terminal non-cleavable hexaHis tag (MGHHHHHHSH), identical to the $\mathrm{N}$-terminal tag provided by the pET15_NESG expression vector.

\section{Cloning of target genes}

The NESG has constructed a Human Cancer Pathway Interaction Network (HCPIN), providing structure-function annotations of key proteins associated with human cancer and developmental biology [9]. The long-range goal of the HCPIN project is to provide a comprehensive 3D structurefunction database for human-cancer-associated proteins and protein complexes in the context of functional networks, using both experimental structures and high quality homology models (i.e., using protein templates with $>80 \%$ sequence identity). Coding regions for 59 human protein targets or domains selected mostly from the HCPIN target list were cloned into both the pWGHisAmp vector for WGCF expression, and into the pET15_NESG vector for $E$. coli intracellular expression. Primer sequences were generated automatically using the Primer, Primer program [8]. The F-primers are 5'-ACCATCACAGCCAT plus gene specific sequences and the R-primers are 5'-GCAGCCGGATCTCGAGCTA plus gene specific sequences. PCR products were cloned into NdeI and XhoI digested pWGHisAmp vector by In-Fusion $^{\mathrm{TM}}$ LIC and transformed into $X L-10$ gold cells. Positive clones were screened first by colony PCR and then confirmed by DNA sequencing. The naming convention for NESG target protein id's is described elsewhere [19]; the corresponding protein sequences are available on the HCPIN web site (http://nesg.org:9090/HCPIN/index.jsp).

T7-based E. coli intracellular protein expression

pET15_NESG plasmids were transformed into BL21(DE3)pMgK cells and expression analysis performed following standard NESG pipeline methods, as described elsewhere [1].

Expression screening a WGCF small-scale batch reaction with FluoroTect ${ }^{\mathrm{TM}}$ detection

Cell-free protein synthesis screening was performed using TNT® SP6 High-Yield WGCF (Promega) and FluoroTect $^{\mathrm{TM}}$ (Promega) in vitro fluorophore labeling of target proteins. DNA was purified using Qiaprep 96 Turbo (Qiagen). For each reaction, $14 \mu \mathrm{L}$ of TNT WGCF lysate (Promega) was mixed with $2 \mu \mathrm{g}$ of plasmids, $0.5 \mu \mathrm{L}$ of FluoroTect ${ }^{\mathrm{TM}}$ (Promega), and nuclease-free $\mathrm{H}_{2} \mathrm{O}$ to a final volume of $20 \mu \mathrm{L}$. These batch reactions were incubated in microfuge tubes at room temperature for $2 \mathrm{~h}$ followed by addition of $1 \mu \mathrm{L}$ of RNase A (Qiagen) to each reaction, and incubated at $37{ }^{\circ} \mathrm{C}$ for $10 \mathrm{~min}$ to hydrolyze unincorporated fluorophore-labeled tRNA. Total protein solubility was determined by SDS PAGE analysis of $1 \mu \mathrm{L}$ of the total reaction compared with the $1 \mu \mathrm{L}$ of the soluble protein supernatant resulting from centrifugation at $3,000 \times g$ at $4{ }^{\circ} \mathrm{C}$ for $10 \mathrm{~min}$. Detection of FluoroTect ${ }^{\mathrm{TM}}$ labeled proteins was accomplished directly by scanning the gels with a laserbased fluorescent gel scanner (Typhoon 8600, GE Healthcare), with excitation of $488 \mathrm{~nm}$ and emission of $532 \mathrm{~nm}$.

Protein production scale-up using WGCF dialysis reaction

Select targets identified as well-expressed and soluble in the HTP FluoroTect screen were subsequently scaled up using a dialysis process. For each $100 \mu \mathrm{l}$ small-scale 
dialysis reaction, $60 \mu \mathrm{L}$ of wheat germ lysate (TNT WGCF) was mixed with $20 \mu \mathrm{g}$ of expression plasmid purified using a Nucleobond Xtra Maxi Plus kit (Macherey-Nagel $\mathrm{GmbH} \& \mathrm{Co}$. KG). Nuclease-free $\mathrm{H}_{2} \mathrm{O}$ was added to obtain the final reaction volume. The reactions were set up in microfuge tubes, transferred into GeBaFlextube mini dialysis cups (Gen Bio-Applications Ltd), and inserted into a $2 \mathrm{~mL}$ microfuge tube containing $1 \mathrm{~mL}$ of dialysis buffer. Dialysis buffer [20] consists of $12 \mathrm{mM}$ HEPES, pH 7.6, $0.5 \mathrm{mM}$ spermidine, $5 \mathrm{mM}$ DTT, $80 \mu \mathrm{M}$ amino acids, $100 \mathrm{mM}$ KOAc, $1.2 \mathrm{mM}$ ATP, $0.1 \mathrm{mM}$ GTP, $10 \mathrm{mM} \mathrm{CP}$, and $1.5 \mathrm{mM} \mathrm{Mg}(\mathrm{OAc})_{2}$. Reactions were incubated at room temperature for $24 \mathrm{~h}$ and then at $4^{\circ} \mathrm{C}$ for 1-2 days before protein expression analysis.

\section{Isotope enrichment}

For isotope enrichment, $2-3 \mathrm{~mL}$ dialysis reactions were carried out using amino-acid-depleted WGCF lysate and ${ }^{15} \mathrm{~N}-,{ }^{13} \mathrm{C}$ enriched amino acids. In these reactions, $1.2-$ $1.8 \mathrm{~mL}$ of TNT WGCF lysate minus amino acids (not yet commercially available) was mixed with $400-600 \mu \mathrm{g}$ of purified plasmid [prepared using a Nucleobond Xtra Maxi Plus kit (Macherey-Nagel GmbH \& Co. KG], and $1 \mathrm{mM}$ (or $100 \mu \mathrm{M}$ ) ${ }^{15} \mathrm{~N}-,{ }^{13} \mathrm{C}$-enriched amino acids (Cambridge Isotopes Laboratories). Nuclease-free $\mathrm{H}_{2} \mathrm{O}$ was added to make up the final reaction volume. ${ }^{15} \mathrm{~N}$-, ${ }^{13} \mathrm{C}$-enriched HR3597B was prepared in two $3 \mathrm{~mL}$ dialysis reactions containing $100 \mu \mathrm{M}{ }^{15} \mathrm{~N}$-, ${ }^{13} \mathrm{C}$-enriched amino acids; ${ }^{15} \mathrm{~N}$, ${ }^{13} \mathrm{C}$-enriched human ubiquitin was prepared in a $2 \mathrm{~mL}$ dialysis reaction containing $1 \mathrm{mM}{ }^{15} \mathrm{~N}-,{ }^{13} \mathrm{C}$-labeled amino acids. The reactions were incubated in $3 \mathrm{~mL}$ Slide-A-Lyzer dialysis cassettes (Pierce) against $100 \mathrm{~mL}$ dialysis buffer containing ${ }^{15} \mathrm{~N}-,{ }^{13} \mathrm{C}$-labeled amino acids (same concentration) at room temperature with gentle stirring for $24 \mathrm{~h}$, and then transferred to $4^{\circ} \mathrm{C}$ for 1-2 days before protein expression analysis.

\section{Protein purification}

To quantitate protein synthesis in the $100 \mu \mathrm{L}$ dialysis reaction, purification was performed using MagneHis (Promega) magnetic beads. The reaction mixture was transferred to a $1.5 \mathrm{~mL}$ microfuge tube and mixed with $350 \mu \mathrm{L}$ of Binding Buffer A (50 mM HEPES, pH 7.5, $500 \mu \mathrm{M} \mathrm{NaCl}$ and $20 \mathrm{mM}$ imidazole), followed by centrifugation $(10,000 \times g$ for $10 \mathrm{~min})$. The supernatant was collected, and $150 \mu \mathrm{L}$ was then transferred to a new microfuge tube containing $30 \mu \mathrm{L}$ of magnetic beads. Following mixing and incubation at room temperature, the magnetic beads were isolated using a 96-Well Magnet Type A (Qiagen), the remaining solution was discarded. Using the same beads this process was repeated for additional $150 \mu \mathrm{L}$ aliquots of supernatant. The beads were washed three times with $150 \mu \mathrm{L}$ of binding buffer using the 96-Well Magnet Type A to capture the magnetic beads. Bound proteins were eluted in $50 \mu \mathrm{L}$ of Elution Buffer (50 mM Tris, $\mathrm{pH} 7.5,500 \mathrm{mM}$ $\mathrm{NaCl}, 500 \mathrm{mM}$ imidazole) and the results visualized by SDS-PAGE analysis.

Mini columns with $0.5-1 \mathrm{~mL}$ of Ni-NTA resin (Qiagen) were used to purify the ${ }^{15} \mathrm{~N}-,{ }^{13} \mathrm{C}$-enriched proteins, synthesized with larger scale dialysis reactions. Briefly, 5 volumes of Binding Buffer B (50 mM Tris, $\mathrm{pH} 7.5$, $500 \mathrm{mM} \mathrm{NaCl}, 40 \mathrm{mM}$ imidazole) were added to the reaction mixtures, followed by centrifugation at $10,000 \times g$ for $10 \mathrm{~min}$. The supernatant was loaded onto a Ni-NTA column and washed with 10 volumes of Binding Buffer. The bound proteins were eluted with Elution Buffer and analyzed by SDS PAGE.

\section{Buffer exchange and sample concentration}

Target-protein containing fractions were pooled and exchanged into $1 \times$ NMR Buffer (20 mM MES, pH 6.5, $200 \mathrm{mM} \mathrm{NaCl}, 10 \mathrm{mM}$ DTT and $1 \times$ Roche Protease Inhibitor Cocktail). In brief, $1 \times$ NMR Buffer was added to the eluate ( $4 \mathrm{~mL}$ final volume), mixed and transferred to a $4 \mathrm{~mL}$ Amicon Ultra centrifugal filter device $(5 \mathrm{kDa}$ MWCO). This was subsequently followed by centrifugation at $3,000 \times g$ at $4^{\circ} \mathrm{C}$ for $40 \mathrm{~min}$. The flow through was discarded and $1 \times$ NMR Buffer was added to the sample to $4 \mathrm{~mL}$ and again centrifuged at $3,000 \times g$ at $4^{\circ} \mathrm{C}$ for $50 \mathrm{~min}$. Remaining sample (about $150 \mu \mathrm{L}$ ) was then transferred to a new $1.5 \mathrm{~mL}$ Amicon Ultra centrifugal filter device ( $5 \mathrm{kDa}$ MWCO) and mixed with $300 \mu \mathrm{L}$ of $1 \times \mathrm{NMR}$ Buffer and centrifuged at $10,000 \times g$ for $40 \mathrm{~min}$ at $4^{\circ} \mathrm{C}$. The flow through solution was discarded and $400 \mu \mathrm{L}$ of $1 \times$ NMR buffer added to the remaining material $(\sim 25 \mu \mathrm{L})$. The sample was again subjected to centrifugation at $10,000 \times g$ for $40 \mathrm{~min}$ at $4^{\circ} \mathrm{C}$. Then another $400 \mu \mathrm{L}$ of $1 \times$ NMR Buffer was added and the sample subjected to a final centrifugation as previously described. ${ }^{2} \mathrm{H}_{2} \mathrm{O}$ and 2 , 2-dimethyl-2-silapentane-5-sulfonic acid (DSS) were added at 10 and $1 \%$, for locking and referencing, respectively. Following buffer exchange into $1 \times$ NMR Buffer and the addition of ${ }^{2} \mathrm{H}_{2} \mathrm{O}$ and DSS, samples we're concentrated down to a volume of about $38 \mu \mathrm{L}$ for NMR measurements.

Labeling efficiency analysis

An aliquot of each purified ${ }^{15} \mathrm{~N}-,{ }^{13} \mathrm{C}$-enriched protein was run on a $4-12 \%$ NuPage SDS-PAGE gel (Invitrogen). Target bands (about $1-2 \mu \mathrm{g}$ ) were excised and submitted to the Biological Mass Spectrometry Facility of the Center for Advanced Technology and Medicine. In-gel tryptic digestions were performed and analyzed on a 4800 MALDI- 
TOF/TOF Analyzer (Applied Biosystems). Theoretical average masses, both labeled and unlabeled, were calculated for several ${ }^{15} \mathrm{~N}$-, ${ }^{13} \mathrm{C}$-enriched tryptic peptides and compared to the average masses observed by mass spectrometry. Labeling efficiency was calculated from the ratio of observed to calculated differences from theoretical unlabeled average mass.

\section{D NMR analysis}

2D ${ }^{15} \mathrm{~N}-{ }^{1} \mathrm{H}$ HSQC spectra were aquired for the WGCFderived proteins ubiquitin $(35 \mu \mathrm{L}, \sim 0.3 \mathrm{mM})$ and HR3597B ( $35 \mu \mathrm{L}$ at $\sim 0.4 \mathrm{mM})$ in NMR buffer. In both cases, the NMR data was collected using the following typical parameters: 64 scans with $64 \mathrm{t}_{1}\left({ }^{15} \mathrm{~N}\right.$-dimension) increments and $2048 \mathrm{t}_{2}\left({ }^{1} \mathrm{H}\right.$-dimension) increments using a $1 \mathrm{~s}$ recycle delay. Total data collection time in each case was $2 \mathrm{~h}$ and $40 \mathrm{~min}$. Data were collected at a temperature of $25^{\circ} \mathrm{C}$ using a Bruker $600 \mathrm{MHz}$ spectrometer fitted with a $1.7 \mathrm{mM}$ micro-cryoprobe. Chemical shifts were referenced to internal DSS.

\section{Results}

\section{Vector engineering}

To date the NESG has created some 5,000 pET-based expression constructs for eukaryotic protein, including expression vectors for 2,963 constructs corresponding to 1,743 human proteins (statistics available on line at www.nesg.org). These E. coli intracellular expression constructs consist of domains and full-length proteins cloned into one of three NESG-modified pET vectors [1]. In 2006, the NESG adopted the In-Fusion ${ }^{\mathrm{TM}}$ (Takara) Ligation Independent Cloning (LIC) method to meet most of its cloning needs. Briefly, LIC cloning, by strand displacement and resection by the InFusion enzyme [14], requires that the target $\mathrm{PCR}$ product share 15 nucleotides complimentary to the site of vector linearization.

The WGCF expression vector pTSHQn from Promega, contains an N-terminal metal-affinity purification tag sequence MASSHQHQHQHQHQAIA (HQ tag) and a kanamycin $\left(\mathrm{kan}^{\mathrm{r}}\right)$ resistance gene for selection. This affinity tag and selection agent differ from those currently employed by the NESG. The pTSHQn vector was accordingly modified to make it more compatible with the existing protein production platform and PCR products. First, pWGHisKan was created by replacing the N-terminal HQ tag and ORF of pTSHQn with a pET15_NESG linker sequence and MGHHHHHHSH non-cleavable hexaHis tag. This change allows the same PCR product to be cloned into both the pET15_NESG vector for bacterial intracellular expression or into pWGHisKan for cell-free expression. Secondly, the kanamycin resistance gene of pWGHisKan was replaced with an ampicillin resistance gene to generate a new fully compatible vector called pWGHisAmp. These changes are depicted graphically in Fig. 1. Proteins produced by either intracellular bacterial expression or WGCF will have the same protein sequence and affinity tag, thereby allowing for parallel cloning and expression screening. However, proteins produced with the WGCF system may exhibit advantageous differences in folding and aggregation properties.

Screening of human protein expression

with the modified WGCF system and comparison with in-cell expression in E. coli

A set of 58 non-structured protein targets (see supplementary data) were selected from the Human Cancer Pathway Protein Interaction Network (HCPIN) [9], along with full length human ubiquitin (sp id: P62988). These targets were cloned into our pET15_NESG and pWGHisAmp vectors. Expression and solubility in the pET15_NESG system was assayed following transformation into BL21(DE3)pMgK E.coli cells. Expression was ranked on a relative scale from 0 to 5 , where 5 indicates the highest levels of expression observed for that system. The degree to which the total protein expressed remained soluble following lysate centrifugation was also represented on a relative scale of $0-5$, where 5 is indicates $>90 \%$ of the expressed protein is in the soluble fraction.

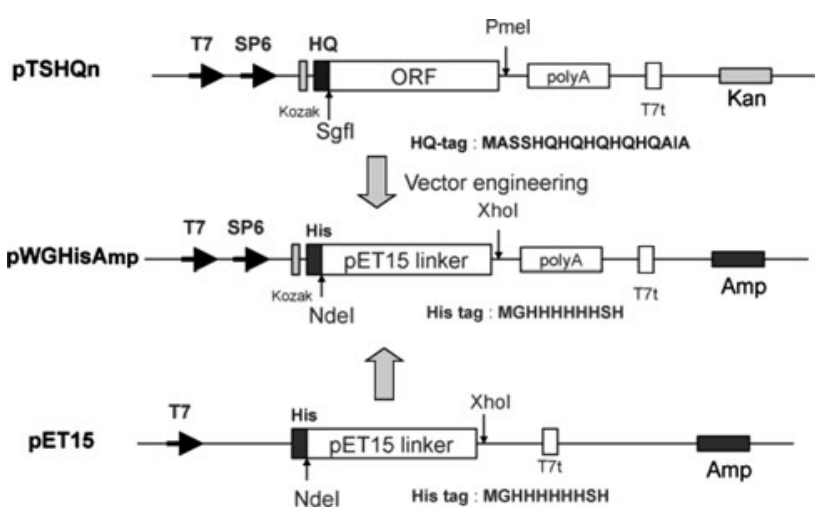

Fig. 1 Vector engineering schema illustrating the creation of the plasmid pWGHisAmp from pTSHQn (Promega), and the NESG modified pET15 vector. PCR and In-Fushion ${ }^{\mathrm{TM}}$ ligation independent cloning methods were used to replace the ORF and HQ metal affinity tag in pTSHQn with the pET15 linker region and 6xHis metal affinity tag to generate pWGHisKan. This was subsequently followed by replacement of the kanamycin resistance gene in pWGHisKan with the pET15 ampicillin resistance gene to generate the final vector pWGHisAmp. PCR derived products can now be cloned into either the NESG modified pET15 bacterial expression plasmid or into the pWGHisAmp plasmid for wheat germ cell-free expression 
In this work, we used the FluroTect ${ }^{\mathrm{TM}}$ GreenLys technology $[6,11]$ to introduce fluorescent-labeled Lys residues at certain AAA codon sites, allowing visualization of target protein even in the presence of high levels of background proteins from the WGCF system itself. The FluoroTect ${ }^{\mathrm{TM}}$ GreenLys in vitro Translation Labeling System allows the fluorescent labeling of translation products through the use of a modified charged lysine tRNA labeled with the fluorophore BODIPY ${ }^{\circledR}-\mathrm{FL}$. Using this system, fluorescently labeled lysine residues are incorporated into nascent proteins during translation. The fluorescent lysine is added to the translation reaction as a charged fluorescent lysinetRNA complex (FluoroTect ${ }^{\mathrm{TM}}$ GreenLys tRNA) rather than a free amino acid. Although only a fraction of the few Lys residues in each protein molecule are modified, it cannot be excluded that the FluoroTect ${ }^{\mathrm{TM}}$ tag affects (negatively or positively) the observed solubility of the targeted protein. In addition, the apparent expression level (i.e., fluorescence intensity) depends on the number of Lys residues that have been substituted with a $\varepsilon$-labeled lysine via the modified tRNA, and can only be compared qualitatively with other methods of protein visualization such as Coomassie Blue dye binding. Further, the fluorescence detection technology is also considerably more sensitive than the aforementioned dye binding. This raises the possibility that solubility may only appear greater as the protein levels detected are below that favoring aggregation. Despite these important caveats, the FluoroTect ${ }^{\mathrm{TM}}$ labeling approach is an excellent first pass screening method for assessing expression and solubility of proteins produced in the WGCF system at relatively low levels compared to background proteins. These targets can then be scaled up without FluoroTect ${ }^{\mathrm{TM}}$ labeling.

E. coli intracellular protein expression and solubility levels were scored for each protein on a scale of $0-5$ for expression (E) in the total cell extract; and on a scale of 0-5 for solubility (S) of the expressed protein in the soluble extract (S) based on Commassie Blue stain binding using SDS-PAGE. In our hands, proteins with a product $E \times S$ (ES score) $>12$ can be scaled up to produce purified proteins at levels of $>20 \mathrm{mg} / \mathrm{L}$. WGCF expression results were scored in a similar way, using FluoroTect ${ }^{\mathrm{TM}}$ labeling with SDS-PAGE gels. These FluoroTect ${ }^{\mathrm{TM}}$ ES scores are not directly comparable to the ES scores for E. coli intracellular expression. In our experience, WGCF FluoroTect ${ }^{\mathrm{TM}}$ ES scores $\geq 8$ can be scaled up (as described below) to provide $50-100 \mu \mathrm{g}$ yields of protein, sufficient for NMR analysis using microprobe NMR technologies that have been described elsewhere [3].

E. coli intracellular expression results were grouped into three classes: proteins with poor expression $(E \leq 1)$, proteins with promising expression $(E \geq 2)$ but poor solubility $(S \leq 1)$, and proteins with both promising
Table 1 Expression and solubility screening results for E. coli intracellular and Promega TNT WGCF expression

\begin{tabular}{lllll}
\hline E. coli & & Total constructs & WGCF ES $\geq 8$ & $\%$ salvage (\%) \\
\cline { 1 - 2 } Exp. & Sol. & & & \\
\hline- & - & 34 & 19 & 46 \\
+ & - & 9 & 6 & 67 \\
+ & + & 16 & 15 & 94 \\
& & 59 & 40 & 68 \\
\hline
\end{tabular}

The scoring protocol is explained in the text

expression $(E \geq 2)$ and solubility $(S \geq 2)$. In Table 1 , Poor expression and solubility in the cell-based system are indicated with a "-" symbol, promising expression and solubility with a "+" symbol.

An SDS-PAGE gel showing results for some of the 59 WGCF screening reactions is presented in Fig. 2. Overall 40 of the 59 human proteins tested $(\sim 70 \%)$ were expressed with ES values greater than 8 in the WGCF system (Table 1). More importantly, of 43 human proteins which could not be produced in the $E$. coli intracellular system (34 with low or no expression and 9 that were expressed but not soluble), 25 were expressed and soluble with ES values $\geq 8$ in the WGCF system (sufficient for NMR analysis). This corresponds to a salvage rate of $\sim 60 \%$ (25/43).

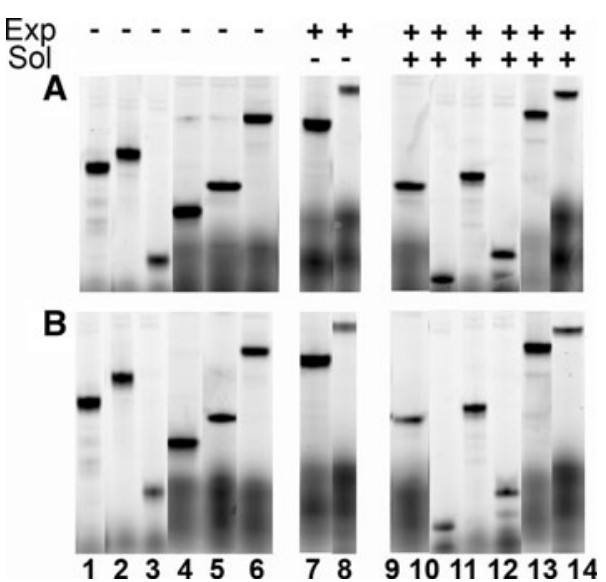

Fig. 2 Total expression (A) and solubility (B) characteristic of 14 human targets, expressed in wheat germ small-scale "batch" reactions, with FluoroTect ${ }^{\mathrm{TM}}$ detection and excitation at 532 and $488 \mathrm{~nm}$, respectively. Expression and solubility characteristics corresponding to in-cell E. coli expressed protein are indicated above the gel ("-" corresponding to poor expression or solubility and "+" indicating promising expression or solubility). The identities by NESG target ID of the proteins in the order listed are as follows: HR2951, HR2928, HR3111, HR2930, HR2934, HR2887, HR2965, HR2924, HR2889, HR2891, HR3007, HR3057, HR3051 and HR2886 (the corresponding protein sequences can be accessed on line at http://nmr.cabm. rutgers.edu:9090/PLIMS/targetSummary.jsf) 
Scale up using dialysis reaction with isotopic enrichment

Consistent with recent work from Promega [20], we observe that the protein yield obtained using the simple batch reaction used above for screening is lower than what can be obtained using a dialysis reaction. Several proteins showing good WGCF expression and solubility in the screening reactions were selected for scale up using the dialysis method. Small scale dialysis reactions (usually $100 \mu \mathrm{L}$ ) were performed before scale-up with labeled amino acids, so as to validate which proteins could be successfully produced prior to isotopic enrichment. Yield at this scale is generally not detectable by SDS-PAGE gel analysis of the whole WGCF reaction mixture without FluoroTect ${ }^{\mathrm{TM}}$ labeling. Therefore, it is necessary to perform IMAC purification followed by SDS-PAGE gel analysis. Several proteins, including some proteins which failed to be produced by $E$. coli intracellular expression, were randomly selected to test on small scale dialysis reaction. After course purification by MagneHis (Promega), all of the selected target proteins were demonstrated to be produced with a yield of about 2-6 $\mu$ g per $100 \mu \mathrm{L}$ dialysis reaction (data not shown).

To test whether the proteins produced by the WGCF system are amenable for structural analysis by NMR, two human proteins (HR3597B and human ubiquitin) were produced with larger scale dialysis reactions containing ${ }^{15} \mathrm{~N}-,{ }^{13} \mathrm{C}$-labeled amino acids. HR3597B, a putative zincbinding protein, showed very low expression in the E. coli intracellular expression system.

${ }^{15} \mathrm{~N}-,{ }^{13} \mathrm{C}$-enriched human ubiquitin was produced using a single $2 \mathrm{~mL}$ dialysis reaction containing $1 \mathrm{mM}$ labeled amino acids; HR3597B was produced using two separate $3 \mathrm{~mL}$ dialysis reactions (total $6 \mathrm{~mL}$ ) with $100 \mu \mathrm{M}$ labeled amino acids. Samples were purified by Ni-NTA IMAC, as described in "Methods and materials", and buffer exchanged to $35-40 \mu \mathrm{L}$ of NMR Buffer. Protein yield and purity was estimated from the SDS-PAGE data in Fig. 3. About $1 \mu \mathrm{L}$ of the ${ }^{15} \mathrm{~N}-,{ }^{13} \mathrm{C}$-enriched ubiquitin NMR buffer exchanged preparation was run in lane 1 of panel 3A. Exactly $10 \mu \mathrm{L}$ of the ${ }^{15} \mathrm{~N}-,{ }^{13} \mathrm{C}$-enriched HR3597B NiNTA-purified sample, and $1 \mu \mathrm{L}$ of the NMR buffer exchanged preparation were run in lanes 1 and 2, respectively of panel 3B. Lysozyme standards at various concentrations were utilized to estimate protein yield. Approximately $120 \mu \mathrm{g}$ of ${ }^{15} \mathrm{~N}$-, ${ }^{13} \mathrm{C}$-enriched ubiquitin was produced from a $2 \mathrm{~mL}$ dialysis reaction $(60 \mu \mathrm{g}$ protein $/ \mathrm{mL}$ dialysis reaction) and about $200 \mu \mathrm{g}$ of ${ }^{15} \mathrm{~N}-{ }^{13} \mathrm{C}$-enriched HR3597B from a $6 \mathrm{~mL}$ dialysis reaction $(30 \mu \mathrm{g}$ protein $/ \mathrm{mL}$ dialysis reaction). Following buffer exchange into NMR Buffer, final concentrations were estimated as $0.3 \mathrm{mM}$ for ubiquitin and $0.4 \mathrm{mM}$ for HR3597B. HR3597B has an ES

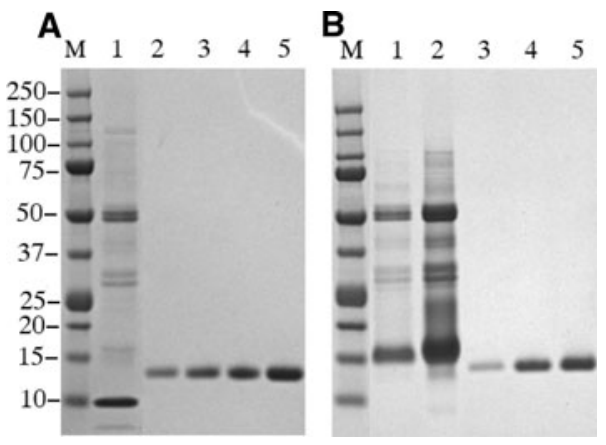

Fig. 3 SDS-PAGE analysis of purified double-labeled protein produced by larger-scale dialysis reaction. Lane $M$ in panels A and $\mathrm{B}$ correspond to Precision Plus Protein Marker (Bio-rad). In panel A, lane 1 was loaded $1 \mu \mathrm{L}$ of purified ${ }^{15} \mathrm{~N}-{ }^{13} \mathrm{C}$-enriched human ubiquitin in NMR buffer ( $40 \mu \mathrm{L}$ preparative volume). In panel B lane 1 was loaded $10 \mu \mathrm{L}$ of Purified HR3597B in elution buffer $(1,900 \mu \mathrm{L}$ preparative volume) and in lane $2,1 \mu \mathrm{L}$ of purified HR3597B in NMR buffer ( $40 \mu \mathrm{L}$ preparative volume). Lanes $2-5$ of panel A contain 0.5, 1.0, 2.0 and $3.0 \mu \mathrm{g}$ of lysozyme and Lanes 3-5 of panel B contain $0.3,1.0$ and $2.0 \mu \mathrm{g}$ of lysozyme

value of 9 in the FluoroTect ${ }^{\mathrm{TM}}$ screening assay, demonstrating that an ES value of 8 is a reasonable threshold for determining which targets may be scaled up for subsequent structural analysis. Contaminating proteins with non-engineered Ni-affinity such as those found at $\sim 50 \mathrm{kDa}$ are from the WGCF lysate itself, and are not isotope-enriched. Therefore, they are not observed in isotope-filtered 2D $\left[{ }^{1} \mathrm{H}^{-15} \mathrm{~N}\right]-\mathrm{HSQC}$ and related triple resonance NMR spectra. Although these proteins do not appear to interfere with NMR studies we are exploring alternative purification methods (HaloTag, Promega; Strep-TagII, Novagen). We have found the former method removes the contaminating bands and that the HSQC spectra of the HaloTag purified HR3597B did not differ significantly from the Ni-NTA purified protein. Although this indicates the contaminating proteins are innocuous, we are in the process of developing alternate purification strategies to allow for production of more homogenous WGCF protein samples.

\section{Labeling efficiency}

MALDI-TOF mass spectroscopy was employed to examine the masses of four tryptic peptides of ${ }^{15} \mathrm{~N}-,{ }^{13} \mathrm{C}$-enriched ubiquitin produced in the presence of 0.1 and $1.0 \mathrm{mM}^{15} \mathrm{~N}-$, ${ }^{13} \mathrm{C}$-labeled amino acids. Using $1.0 \mathrm{mM}$ concentrations of labeled amino acids in the cell free expression media, typical labeling efficiencies are generally $>90 \%$ (Table 2 ). We observe a 1.3-fold enhancement in labeling efficiencies with the $1.0 \mathrm{mM}$ labeled amino acid supplemented dialysis mixture relative to the reaction using $0.1 \mathrm{mM}$ concentration (Table 2). It is not known if the same enhancement in labeling efficiency could be optimized with intermediate concentrations of labeled amino acids (e.g. $0.5 \mathrm{mM}$ ) in the 
Table 2 Labeling efficiency of ubiqutin produced using the modified Promega TNT WGCF system with two different concentrations of labeled amino acids in the reaction mixture

\begin{tabular}{llll}
\hline Peptide sequence & Position & $0.1 \mathrm{mM}$ labeled aa's $(\%)$ & $1 \mathrm{mM}$ labeled aa's (\%) \\
\hline EGIPPDQQR & $44-52$ & 68.9 & 93.7 \\
ESTLHLVLR & $74-82$ & 73.4 & 96.4 \\
IQDKEGIPPDQQR & $40-52$ & 66.6 & 94.0 \\
TITLEVEPSDTIENVK & $22-37$ & 77.2 & 93.2 \\
\hline
\end{tabular}

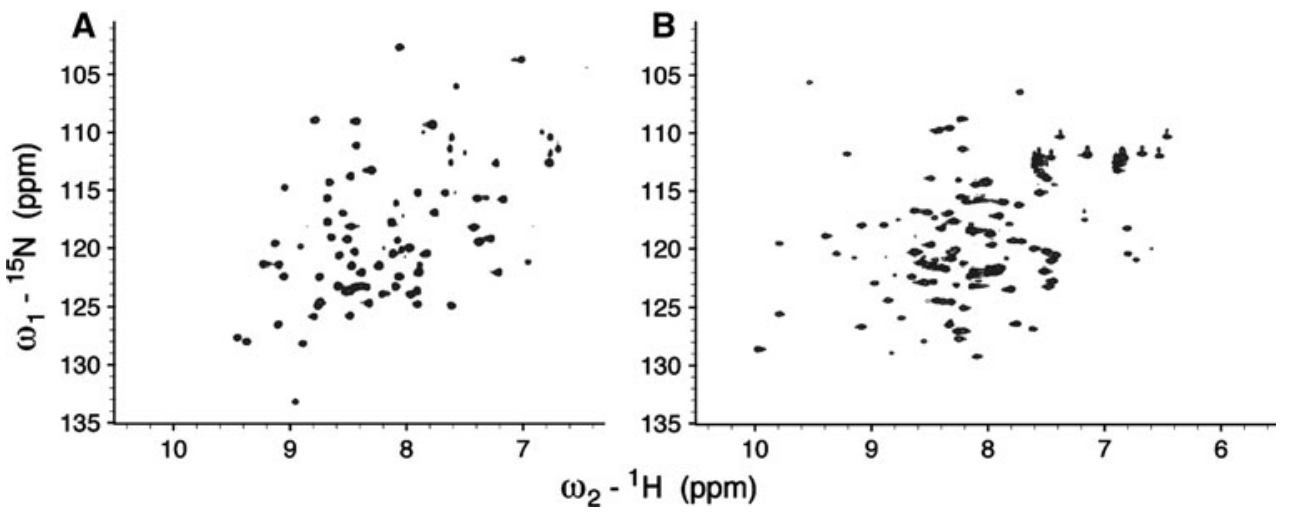

Fig. 4 Micro cryo NMR probe ${ }^{15} \mathrm{~N}-{ }^{1} \mathrm{H}$ 2D HSQC spectra at $25^{\circ} \mathrm{C}$ of $\mathbf{A}$ human ubiquitin and B NESG human protein target HR3597B produced with

${ }^{15} \mathrm{~N},{ }^{13} \mathrm{C}$-enrichment using the Promega TNT ${ }^{\circledR}$ WGCF system. Spectra were obtained using a $600 \mathrm{MHz} 1.7 \mathrm{~mm}$ Bruker micro cryo NMR probe using 100$200 \mu \mathrm{g}$ of protein sample each small $(<10 \mathrm{kDa})$ proteins can be determined by NMR using $<100 \mu \mathrm{g}$ quantities of protein samples with micro NMR probes [3]. These technologies are enhanced by the recent introduction of Bruker micro cryo NMR probes, like the one used in this work. Thus, there is a natural synergy between WGCF protein expression and micro cryo NMR probe technologies. In addition, WGCF systems can accommodate selective labeling strategies for single proteins-something that cannot easily be achieved in whole cell systems. This includes incorporation of SAIL ("Stereo Array Isotope Labeling") amino acids, which are valuable for NMR studies of larger proteins [10].

In this work, modifications were made to pTSHQn, a TNT $^{\circledR}$ SP6 High-Yield WGCF expression system vector, to enable parallel implementations of WGCF and in-cell pET vector cloning strategies. Using this system we have assessed expression and solubility for 59 NESG human protein targets, $\sim 60 \%$ of which could not be expressed in a soluble form in our E. coli intracellular pET system. Forty of these human proteins were produced at levels sufficient to be considered for NMR studies $(>100 \mu \mathrm{g})$ using the TNT WGCF system; 25 of these could not be produced in soluble form using the cell-based $E$. coli system. Modifications were made in the TNT WGCF system by depletion of amino-acids from the lysate, to allow incorporation of labeled amino acids. Human ubiquitin and NESG human protein target HR3597B were ${ }^{15} \mathrm{~N}$-, ${ }^{13} \mathrm{C}$-enriched, and purified using a modified TNT WGCF medium. Each reaction produced $\sim 30-60 \mu \mathrm{g}$ of labeled protein per $\mathrm{mL}$ of WGCF dialysis reaction volume. In this work, TNT WGCF expression and micro cryo NMR probe technology were combined for the first time, and promising HSQC results 
were obtained for the two test proteins, suggesting that the structural analysis by NMR of such WGCF produced proteins will become routine in the not-so-distant future.

Acknowledgments We thank Colleen Ciccosanti, James Hartnett, Janet Huang, Li-Chung Ma, Melissa Maglaqui, Dongyan Wang, and Rong Xiao for helpful discussions. We also thank Haiyan Zheng, Caifeng Zhao, Meiqian Qian and Peter Lobel of the Biological Mass Spectrometry Facility at CABM for MALDI-TOF analysis of isotope enriched proteins. This work was supported by grant U54-GM074958 from the Protein Structure Initiative of National Institute of General Medical Sciences.

Open Access This article is distributed under the terms of the Creative Commons Attribution Noncommercial License which permits any noncommercial use, distribution, and reproduction in any medium, provided the original author(s) and source are credited.

\section{References}

1. Acton TB, Gunsalus KC, Xiao R, Ma LC, Aramini J et al (2005) Robotic cloning and protein production platform of the Northeast Structural Genomics Consortium. Methods Enzymol 394:210243

2. Aoki M, Matsuda T, Tomo Y, Miyata Y, Inoue M, Kigawa T, Yokoyama S (2009) Automated system for high-throughput protein production using the dialysis cell-free method. Protein Expr Purif 68(2):128-136

3. Aramini JM, Rossi P, Anklin C, Xiao R, Montelione GT (2007) Microgram-scale protein structure determination by NMR. Nat Methods 4(6):491-493

4. Busso D, Kim R, Kim SH (2004) Using an Escherichia coli cellfree extract to screen for soluble expression of recombinant proteins. J Struct Funct Genomics 5(1-2):69-74

5. Cheng J, Randall AZ, Sweredoski MJ, Baldi P (2005) SCRATCH: a protein structure and structural feature prediction server. Nucleic Acids Res 33(Web Server issue): W72-W76

6. Coleman MA, Lao VH, Segelke BW, Beernink PT (2004) Highthroughput, fluorescence-based screening for soluble protein expression. J Proteome Res 3(5):1024-1032
7. Endo Y, Sawasaki T (2006) Cell-free expression systems for eukaryotic protein production. Curr Opin Biotechnol 17(4):373380

8. Everett JK, Acton TB, Montelione GT (2004) Primer Prim'er: a web based server for automated primer design. J Struct Funct Genomics 5(1-2):13-21

9. Huang YJ, Hang D, Lu LJ, Tong L, Gerstein MB et al (2008) Targeting the human cancer pathway protein interaction network by structural genomics. Mol Cell Proteomics 7(10):2048-2060

10. Kainosho M, Torizawa T, Iwashita Y, Terauchi T, Mei Ono A et al (2006) Optimal isotope labelling for NMR protein structure determinations. Nature 440(7080):52-57

11. Kobs G, Hurst R, Betz N, Godat B (2001) FluoroTect ${ }^{\mathrm{TM}}$ GreenLys in vitro translation labeling system. Promega Notes 77:23-27

12. Kohno T (2005) Production of proteins for NMR studies using the wheat germ cell-free system. Methods Mol Biol 310:169-185

13. Kohno T, Endo Y (2007) Production of protein for nuclear magnetic resonance study using the wheat germ cell-free system. Methods Mol Biol 375:257-272

14. Marsischky G, LaBaer J (2004) Many paths to many clones: a comparative look at high-throughput cloning methods. Genome Res 14(10B): 2020-2028

15. Morita EH, Shimizu M, Ogasawara T, Endo Y, Tanaka R et al (2004) A novel way of amino acid-specific assignment in (1) $\mathrm{H}-(15) \mathrm{N}$ HSQC spectra with a wheat germ cell-free protein synthesis system. J Biomol NMR 30(1):37-45

16. Netzer WJ, Hartl FU (1997) Recombination of protein domains facilitated by co-translational folding in eukaryotes. Nature 388 (6640):343-349

17. Vinarov DA, Loushin Newman CL, Markley JL (2006) Wheat germ cell-free platform for eukaryotic protein production. FEBS J 273(18):4160-4169

18. Vinarov DA, Lytle BL, Peterson FC, Tyler EM, Volkman BF et al (2004) Cell-free protein production and labeling protocol for NMR-based structural proteomics. Nat Methods 1(2):149-153

19. Wunderlich Z, Acton TB, Liu J, Kornhaber G, Everett J et al (2004) The protein target list of the Northeast Structural Genomics Consortium. Proteins 56(2):181-187

20. Zhao KQ, Hurst R, Slater MR, Bulleit RF (2007) Functional protein expression from a DNA based wheat germ cell-free system. J Struct Funct Genomics 8(4):199-208

21. Zhu B, Cai G, Hall EO, Freeman GJ (2007) In-fusion assembly: seamless engineering of multidomain fusion proteins, modular vectors, and mutations. Biotechniques 43(3):354-359 